\title{
Multiculturalismo, pesquisa e formação de professores: $o$ caso das Diretrizes Curriculares para a Formação Docente ${ }^{1}$
}

\author{
Ana Canen
}

Giseli Pereli de Moura Xavier

\section{Resumo}

$\bigcirc$ presente artigo discute possibilidades de articulação de uma perspectiva multicultural ao componente de pesquisa na formação docente, analisando implicações de tal articulação e discutindo a extensão em que está presente no discurso das Diretrizes Curriculares de Formação de Professores (BRASIL, 2000b). Em um primeiro momento, discute o multiculturalismo e a pesquisa, como componentes da formação de professores, levantando tensões e possibilidades em sua articulação; em seguida, relata o contexto em que emergem as recentes políticas educacionais e analisa ênfases e silêncios das diretrizes curriculares nacionais de formação de professores, com relação ao papel da pesquisa e do multiculturalismo em suas formulações. Conclui, indicando a necessidade de se concretizar estratégias multiculturais na formação docente que permitam superar binômios tais como o que separa pesquisa acadêmica de pesquisa prática nessa formação.

Palavras-chave: Multiculturalismo. Pesquisa. Formação de professores. Diretrizes curriculares de formação de professores.

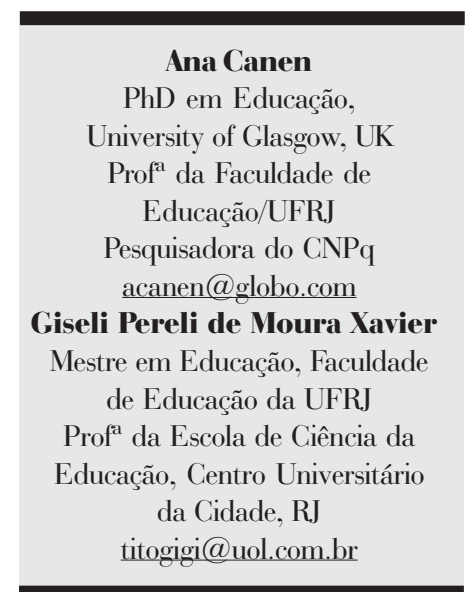
analyses implications of such an intertwinement and discusses the extent to which those components are present within the discourse of the Brazilian National Curricular Guidelines for Teacher Education

${ }^{1}$ Texto baseado na apresentação preparada para: Formação de Professores: uma discussão em curso; Curso de Extensão, Fórum de Cultura, CFCH, Universidade Federal do Rio de Janeiro, 10 de novembro de 2002. 
(BRASIL, 2000b). Firstly, it discusses multiculturalism and research as components of teacher education, raising tensions and possibilities of articulating both; afterwards, it discusses the context in which recent educational policies emerge and analyses emphases and silences in the national curricular guidelines as related to the role of research and of multiculturalism in its proposals. It concludes, indicating possible multicultural ways by which research could be worked out in teacher education so as to challenge dichotomies, such as the one that separates academic and practical research in teacher education. Keywords: Multiculturalism. Research. Teacher education. Brazilian National Curricular Guidelines for Teacher Education.

\section{Resumen \\ Multiculturalismo, pesquisa y formación de profesores: el caso de las directrices curriculares para la formación docente}

Este artículo discute las posibilidades de articulación de la perspectiva multicultural al componente de pesquisa en la formación docente, analizando implicaciones de tal articulación y discutiendo la extensión en que está presente en el discurso de las Directrices Curriculares de Formación de Profesores (BRASIL, 2000b). En un primer momento, discute el multiculturalismo y la pesquisa, como componentes de la formación de profesores, levantando tensiones y posibilidades en su articulación; a continuación, relata el contexto en que emergen las recientes políticas educativas y analiza énfasis y silencios de las directrices curriculares nacionales de formación de profesores, con relación al papel de la pesquisa y del multiculturalismo en sus formulaciones. Concluye, señalando la necesidad de concretizar estrategias multiculturales en la formación docente que permitan superar binomios tales como el que separa la pesquisa académica de la pesquisa práctica en esta formación.

Palabras clave: Multiculturalismo. Pesquisa. Formación de profesores. Directrices curriculares de formación de profesores.

\section{Introdução}

$\bigcirc$ fato de que vivemos em sociedades multiculturais, desiguais, tem sido reconhecido, cada vez mais, no novo milênio. Conforme atestam conferências internacionais como a recentemente conduzida em Durban, África do Sul, a necessidade de valorização das identidades plurais de gênero, raça, padrões lingüísticos, étnicos, culturais e outros, passa a emergir com força, resultante particularmente dos movimentos sociais e organizações não governamentais em todo o mundo. Nesse contexto, preparar professores para atuarem em sociedades multiculturais, constituídas na pluralidade, na multiplicidade e nas diferenças, é ressaltado na literatura nacional e internacional (CANEN, 1997, 2000, 2001a, 2001 b; 2002; GRANT, 2000; McLAREN, 2000; PINTO, 1999). Em contraposição a modelos de formação docente assentados em uma pretensa homogeneidade social, a perspectiva multicultural focaliza caminhos teóricos e estratégias pedagógicas para a preparação de professores aptos a atuarem no contexto multicultural e desigual em que se insere a educação, de forma a valorizar a pluralidade cultural e desafiar estereótipos e preconceitos a ela relacionados. 
Nesse sentido, temos argumentado que o modelo de professor pesquisador, como um profissional reflexivo que assume a postura de constante reflexão crítica sobre a prática pedagógica, atuando ativamente na construção de seu conhecimento pedagógi$\mathrm{co}$, poderia articular-se a posturas multiculturais, de forma a promover a formação do professor-pesquisador multiculturalmente comprometido. Tal articulação poderia oferecer um caminho possível no sentido da superação daquilo que Hoover (1994) denominou de redução da reflexão do professor-pesquisador a aspectos imediatamente relacionados à sua prática imediata, em detrimento de uma postura crítica que situe esta prática no contexto social e cultural maior que a informa. Nesse sentido, argumentamos que o modelo do professor-pesquisador multiculturalmente comprometido pode representar um via pela qual conexões entre o universo microssocial da sala de aula e a realidade cultural e social mais ampla possa se efetuar, com vistas a possibilitar desafios a discursos que congelam identidades e reforçam preconceitos. Desse modo, o modelo do professor-pesquisador multiculturalmente comprometido pode representar um possível caminho de transformação da desigualdade educacional que atinge, justamente, grupos culturais e étnicos cujos padrões não estão contemplados nos discursos curriculares abraçados pela escola.

Entretanto, como tem sido pensada a articulação ensino-pesquisa e multiculturalismo na formação de professores, na literatura na área? Que significados pode assumir e que desafios e potenciais apresenta para esta formação? Ao mesmo tempo, em que medida tem sido contemplada nas políticas de formação docente, conforme ilustrado nas Diretrizes Curriculares de Formação de Professores (BRASIL, 2000b, p. 6) ${ }^{2}-$ documento produzido com a intenção de rever os modelos de formação docente, objetivando "a proposição de orientações gerais que apontam na direção da profissionalização do professor e do atendimento às necessidades atuais da educação básica na sociedade brasileira?" Essas questões mobilizam o presente texto, que está estruturado do seguinte modo: em um primeiro momento, discute o multiculturalismo e a pesquisa, como componentes da formação de professores, levantando tensões e possibilidades em sua articulação; em um segundo momento, relata o contexto em que emergem as recentes políticas educacionais, dentre as quais aquelas referentes à formação de professores, analisando criticamente suas ênfases e silêncios; em um terceiro momento, mergulha sobre o discurso das diretrizes curriculares nacionais de formação de professores, focalizando particularmente o papel da pesquisa e do multiculturalismo em suas formulações.

\section{Multiculturalismo e Pesquisa na Formação de Professores: o desafio da polissemia}

Vivemos em sociedades multiculturais, marcadas pela pluralidade e também pela desigualdade. Nesse contexto, ganha relevância o multiculturalismo - cujo conceito é normalmente definido como o de um campo teórico, prático e político, voltado à va-

\footnotetext{
2 As Diretrizes Curriculares Nacionais para a Formação de Professores da Educação Básica, foram oficialmente instituídas em 18/ 02/2002 por meio da Resolução CNE/CP 1/2002. Este artigo se refere à "Proposta de Diretrizes para a Formação Inicial de Professores da Educação Básica, em Cursos de Nível Superior", de maio de 2000.
} 
lorização da diversidade cultural e ao desafio aos preconceitos (CANEN, 1997, 1999, 2000, 2001a, 2001b, 2002; CANEN; MOREIRA, 2001 ; GRANT, 2000; McLAREN, 2000). Na educação, o multiculturalismo informa, por exemplo, perspectivas curriculares que articulam conteúdos específicos a questionamentos sobre a construção de preconceitos e à valorização da pluralidade cultural. Canen e Oliveira (2002) ilustram essa articulação, ao analisarem os dados de um estudo de caso de cunho etnográfico que acompanhou o cotidiano da prática pedagógica de uma professora de Ciências, em que tópicos tais como "pele" eram tratados não apenas do ponto de vista biológico, mas também a partir de textos de outras áreas que questionavam a discriminação baseada na cor desse órgão do corpo, mostrando sua inadequação e insustentabilidade científica.

Influências do pensamento multicultural têm sido sentidas em movimentos que buscam a valorização dos padrões plurais e, ao mesmo tempo, enfatizam a necessidade da adoção de medidas de reparação a injustiças e preconceitos com relação a identidades culturais, raciais, étnicas, de gênero e outras marginalizadas nos processos sociais, nos quais se inclui a educação. É neste contexto que surgem propostas curriculares que incluem a diversidade cultural em seus eixos, como, exemplo, os Parâmetros Curriculares Nacionais - PCNs, em que um dos temas transversais é a diversidade cultural e a ética.

Ao mesmo tempo, em nome do multiculturalismo, ações afirmativas são desenvolvidas, que buscam a representação das identidades culturais plurais nos espaços educacionais e nos currículos. Dentre essas, a políti- ca de reserva de cotas para negros e alunos de escolas públicas para o ingresso nas universidades tem tido destaque na mídia, ainda que seja objeto de problematização no âmbito do próprio pensamento multicultural, polarizado entre percepções que consideram tal medida como multiculturalmente orientada e outras que a percebem, tão somente, como uma ação de homogeneização cultural, na medida em que se volta à inserção das identidades em pauta num sistema "universal" de ensino. Ainda que tais políticas não sejam objeto do presente artigo, vale destacar que, pari passu às mesmas, o multiculturalismo aponta para a necessidade de ações preventivas, mais do que reparadoras, que atinjam os cotidianos das instituições educacionais no sentido de fomentar o diálogo entre as diferenças e questionar discursos que congelam as identidades e que reforçam as discriminações e os estereótipos.

Formar o professor multiculturalmente orientado implica, conforme temos argumentado, em trabalhar em prol de um modelo de professor apto a compreender o conhecimento e o currículo como processos discursivos, marcados por relações de poder desiguais, que participam da formação das identidades. Implica em tensionar conteúdos pré-estabelecidos e pretensões a verdades únicas, procurando detectar vozes silenciadas e representadas nesses discursos curriculares, de forma a mobilizar a construção de identidades docentes sensíveis à diversidade cultural e aptas a formular alternativas discursivas transformadoras, desafiadoras do congelamento de identidades e dos estereótipos.

Entretanto, argumentamos que a diversidade cultural não representa a anulação da ciência. Contrapondo-nos a um relativismo total, sustentamos que, ainda 
que sofram influência ideológica, os currículos podem representar espaços discursivos em que o global e o local se articulam, em sínteses e hibridizações criativas. Trata-se, no nosso entender, de buscar a articulação de conhecimentos percebidos como "universalmente" aceitos, incluindo as últimas conquistas da tecnologia, de um lado, e o olhar sobre a diversidade cultural com a qual propostas curriculares irão interagir, de outro.

Buscando avançar em tais reflexões, argumentamos que tal modelo implica em um papel central para a pesquisa, na medida em que, ao ressaltar o contingente, o plural, o local, rejeitam-se narrativas mestras e aposta-se na construção de alternativas novas, criativas e críticas. Tais alternativas não emergem senão pela via da pesquisa que, em uma perspectiva multicultural, propicia a problematização da realidade e a busca de caminhos teóricos e metodológicos viabilizadores de discursos desafiadores da homogeneização cultural e dos preconceitos com relação a grupos percebidos como "diferentes". É importante salientar que, ainda que o presente artigo focalize o ensino e a pesquisa na formação docente, tais categorias não esgotam o campo de reflexões nessa área, que deveria incidir sobre uma problematização sobre o próprio conceito de educação, de modo que não se caia em subjetivismos e olhares relativistas, de um lado, e, de outro, que não se proceda a um engessamento em propostas tidas como universais que informam práticas reprodutoras. A articulação entre o respeito pelas diversas culturas a uma visão voltada ao permanente aprimoramento humano, com todas as tensões inerentes a esta dialética, informa nossa argumentação.
Nesse sentido, articular ensino e pesquisa na formação docente representa um caminho possível para se pensar em transformar essa realidade no sentido de valorizar a pluralidade cultural e a formação de identidades docentes e discentes multiculturalmente comprometidas. Entretanto, ainda que multiculturalismo e pesquisa possam ser dimensões relativamente bem aceitas como horizontes para o trabalho com a formação de professores, desafios surgem ao se pensar nos fatores envolvidos no refinamento de suas propostas e na sua concretização. Questões surgem relativas ao que realmente se entende por multiculturalismo e pesquisa, que tipos de abordagens devem ser abraçadas com relação a ambos os conceitos e que desdobramentos possuem no cotidiano da formação de professores. No que se refere ao multiculturalismo, temos apontado vertentes desde as mais folclóricas e pouco problematizadoras (que se limitam a tratar da diversidade cultural em termos de festas, receitas, costumes e ritos) até outras mais críticas (que questionam relações desiguais de poder e preconceitos, buscando desafiá-los), passando, também, por posturas multiculturais críticas pós-modernizadas (que alertam para os impactos dos discursos na formação das identidades plurais, buscando construir discursos alternativos que levem em conta o hibridismo identitário) (CANEN, 2002).

No horizonte dessa polissemia, contradições e posturas problemáticas surgem nos debates multiculturais. Certos autores, como Glazer (1997), por exemplo, crêem que o ideal multicultural não deveria fomentar posturas sectárias, que abalassem a "harmonia social", particularmente no âmbito das escolas e da formação de professores. Nesse caso, tais autores propõem deixar de lado 
temas "polêmicos" como racismo, xenofobia e outras questões caras ao multiculturalismo em sua vertente mais crítica, ou então, se necessário, trazê-los à tona em uma ótica positiva, otimista, indicando avanços da sociedade em seu enfrentamento, de modo a não recair em "polarizações" e/ou radicalizações de posturas. Por outro lado, no entanto, autores como McLaren (2000) e Gilroy (2000) acreditam que o multiculturalismo deveria, justamente, partir da denúncia das assimetrias de poder para buscar alternativas de ações revolucionárias, transformadoras, no âmbito da educação e da formação de professores. Nesse caso, temas como racismo, xenofobia, homofobia e outros deveriam, no entender de tais autores, constituir o cerne dos discursos de formação docente, de modo a desafiar sua gênese e pensar em discursos alternativos, híbridos, transformadores. A partir da polissemia do multiculturalismo brevemente esboçada, revela-se a complexidade da tradução do ideal multicultural para propostas teórico-metodológicos que o incorporem no cotidiano da formação docente.

Da mesma forma que o multiculturalismo, a dimensão da pesquisa como inerente a um preparo de professores como autores de seus projetos profissionais e não como meros "consumidores" de produtos desenvolvidos por outros parece ser consensual, quando interpretada a nível mais genérico. Entretanto, tal como no multiculturalismo, uma vez analisado em suas dimensões mais concretas, o binômio ensino-pesquisa também suscita desafios e questionamentos. Autores como Lüdke (2001) e André (2001) têm traçado um panorama dos dilemas e problemas apontados com relação a esse binômio. Tais autoras mapearam, por exemplo, desde a presença de argumentos que defendem tal articulação, mas que acreditam que a pesquisa na formação de professores deveria ter um caráter prático (ou seja, ser ligada diretamente à prática pedagógica do professor), até outras posturas de autores que afirmam que justamente a pesquisa, tida como mais "tradicional" ou "acadêmica", seria a que poderia conferir um distanciamento crítico do professor com relação a seu cotidiano, possibilitando-lhe maiores probabilidades de agir de forma transformadora sobre essa mesma prática.

Concordando com autores tais como Queiroz (1998) e Wilson (1998), temos argumentado que o confronto pesquisa científica (teórica) - pesquisa pedagógica (ligada diretamente à prática docente) pouco tem contribuído para se avançar na formulação de caminhos que viabilizem a pesquisa como dimensão necessária à formação docente (CANEN; ANDRADE, 2001). Em uma perspectiva multicultural, temos reforçado que a superação de binômios tais como preto-branco, pesquisa quantitativa-pesquisa qualitativa e assim por diante, significa visualizar a pesquisa enquanto fruto de argumentação construída a partir dos universos culturais e dos paradigmas dos pesquisadores, admitindo-se possibilidades de ressignificações e hibridizações plurais. Nesse sentido, teoria e prática não podem ser vistas como pólos, binômios irreconciliáveis, mas como partes constitutivas do espectro da pesquisa em educação.

Entretanto, em que medida tal modelo de formação de professores encontra eco nas políticas educacionais brasileiras? Em que medida as questões e desafios surgidos na articulação multiculturalismo - pesquisa são levantados no âmbito de seus discursos curriculares? É o que discutiremos a seguir. 


\section{Multiculturalismo $\mathrm{x}$ Formação de Professores para o Mercado: um quadro contraditório nas políticas educacionais}

Apontamos, na última sessão, que a valorização da diversidade cultural tem sido trazida à tona em conferências mundiais e em políticas de ações afirmativas. Da mesma forma, a presença da diversidade cultural foi apontada no contexto de políticas curriculares, como os Parâmetros Curriculares Nacionais (1998), que apresentam-na como tema transversal a ser trabalhado pelas escolas ${ }^{3}$. A tendência de se incorporar sensibilidades multiculturais em políticas educacionais, no entanto, parece tensionada por ações que visam à homogeneização da educação nesse mesmo quadro, revelada no ímpeto, registrado nos últimos anos, em legislar diretrizes e parâmetros nacionais comuns para todo o território nacional.

Longe de ser limitada ao Brasil, a tensão homogeneização e multiculturalismo tem sido destacada como aquela que caracteriza o paradigma do novo milênio. De fato, conforme discutido na seção anterior, se a multiculturalidade tem assumido discussões de ponta em conferências e tem sido o mote de candidatos a cargos políticos (nas últimas eleições brasileiras para presidente, ambos os candidatos que permaneceram para o turno final defendiam a política de cotas raciais nas universidades), ao mesmo tempo tem sido tensionada por outras perspectivas que tendem a ver a globalização como sinônimo de homogeneização cultural, embasando propostas e políticas educacionais assentadas na listagem de atributos tidos como "universais" e cruciais para a inserção dos sujeitos no mercado de trabalho.

É nesta última perspectiva que, ao final da década de 80 e no início da década de 90, toma novo "fôlego" e se consolida, na pauta das políticas e discussões educacionais, o debate em torno do campo da formação de professores. A partir da promulgação da nova Lei de Diretrizes e Bases da Educação em 1996 - LDB 9.394/96 (BRASIL, 1996), várias medidas passam a ratificar um conjunto de reformas propostas pelo governo anterior e que ainda não foram questionadas ou modificadas pelo governo atual, dentre as quais destacam-se: os Referenciais para Formação de Professores (BRASIL, 1999), o Projeto de Estruturação do Curso Normal Superior (BRASIL, 2000a) e a instituição de Diretrizes para a Formação Inicial de Professores da Educação Básica em Cursos de Nível Superior (CONSELHO NACIONAL DE EDUCAÇÃO, 2002) - foco do presente trabalho, a ser analisado a seguir.

\section{Pesquisa, Multiculturalismo e Diretrizes Curriculares Nacionais para a Formação Docente: que possibilidades? Que omissões?}

Interessa-nos, no limite do presente artigo, apontar a extensão em que pretensões de valorização da diversidade cultural e da pesquisa na formação de professores, que emergem esporadicamente no âmbito das políticas educacionais acima citadas,

\footnotetext{
${ }^{3}$ Para uma análise das potencialidades e contradições desse discurso curricular com relação ao multiculturalismo, vide Canen (2000).
} 
tensionam-se com discursos que homogeneizam esta formação. De fato, o primeiro aspecto que chama a atenção ao se analisarem as diretrizes curriculares em pauta é o foco sobre a categoria "competências", percebida como base de uma profissionalização docente. Embora a discussão deste conceito não seja foco do presente trabaIho, é importante assinalar que, ao apresentar a categoria "competências" como o eixo de uma prática docente dentro de uma perspectiva profissional, as diretrizes contrapõem-se a modelos de formação docente que tomam a categoria pesquisa como o centro desta mesma formação e da profissionalização do "ser professor".

Além de secundarizar a pesquisa na visão profissional do professor, o discurso das Diretrizes ainda apresenta reduções quanto à interpretação de sua função na formação de professores. De fato, ao apontar "problemas" com relação à formação docente efetuada no Brasil, tal discurso destaca, dentre outros, a "inadequação do tratamento da pesqui$\mathrm{sa}^{\prime \prime}$ e a "desconsideração das especificidades próprias dos níveis e/ou modalidades de ensino em que são atendidos os alunos da educação básica" ${ }^{\prime}$. Uma investigação sobre as tendências na análise de tais "problemas", no âmbito das diretrizes, revela duas tendências que parecem persistir em toda a narrativa do documento, quais sejam: a) uma separação entre pesquisa sobre a prática docente e pesquisa dita acadêmica, com forte ênfase na primeira como componente necessário para a formação de professores, em detrimento da segunda; b) uma compreensão das "especificidades" e da diversidade cultural de alunos da educação básica ora como "desvio" com relação a uma normalidade cognitiva longe de ser problematizada, ou como um aspecto folclórico, exótico, até mesmo "interessante", a ser trabalhado pelo futuro professor para enriquecer sua prática (mas não como eixo configurador de reflexões críticas que permitam o questionamento sobre processos de construção de diferenças e preconceitos, como preconizado por posturas críticas multiculturais).

No que se refere ao item a, ao qual nos voltamos agora, é importante ressaltar que, ao falar da "inadequação do tratamento da pesquisa" dado por cursos de formação de professores, o documento explicita claramente a visão de pesquisa entendida como reflexão direta e imediata sobre a prática docente, como se percebe a seguir:

A preocupação de que o professor desenvolva uma postura investigativa sobre sua área de atuação e que aprenda a usar procedimentos de pesquisa como instrumentos de trabalho é um aspecto em geral ausente na formação de professores [...] embora muitos formadores se preocupem em apresentar algumas pesquisas desenvolvidas na área educacional a seus alunos - como, por exemplo, os trabalhos de Piaget e Vigotsky - geralmente, não há um trabatho de interpretação e uso dessas pesquisas na prática pedagógica, o que leva o futuro professor a criar representações de que a 'teoria na prática é outra' (BRASIL, 2000b, p. 30).

Conforme argumentamos, a articulação das reflexões teóricas à prática pedagógica é relevante, sob risco de se isolar ambas em compartimentos estanques. Entretanto, se a ênfase na teoria - como sutilmente aponta-

\footnotetext{
${ }^{4}$ BRASIL, 2000b, p. 30.

${ }^{5}$ Id., Ibid., 2000 b, p. 32.
} 
do no extrato acima, ao referir-se a pesquisas desenvolvidas por Piaget e Vigotsky em detrimento da reflexão sobre a prática é limitadora de uma formação de professores que se pretende transformadora, da mesma forma o peso exclusivo à pesquisa sobre a prática - detectada também por Lüdke (2001) nos argumentos defendidos por autores como Demo, Elliott e outros, significa, no nosso entender, uma permanência do binômio pesquisa prática - pesquisa acadêmica, como pólos separados.

Infelizmente, entretanto, o binômio pesquisa prática-pesquisa acadêmica persiste em grande parte do documento, como se verifica no extrato a seguir, retirado das formulações contidas em seu discurso, referentes a princípios orientadores para uma reforma da formação de professores, também destacado criticamente por André (2001):

A pesquisa (ou investigação) que se desenvolve no âmbito do trabalho do professor não pode ser confundida com a pesquisa acadêmica ou pesquisa científica. Refere-se, antes de mais nada, a uma atitude cotidiana de busca de compreensão dos processos de aprendizagem [...] e dos conhecimentos que constituem seus objetos de ensino. (BRASIL, 2000b, p. 45).

De fato, o extrato acima parece deixar clara a ênfase no primeiro "tipo" de pesquisa do binômio em pauta, a saber, a dita "pesquisa prática". Nesse sentido, como temos argumentado, tanto a super-valorização da pesquisa dita acadêmica, ou daquela diretamente ligada à prática (como parece ser o caso do documento em análise), em detrimento da visualização da pes- quisa como um fenômeno global, híbrido e multicultural (e, portanto, situado acima de tais binômios), poderia comprometer seu impacto sobre a formação de professores

No que se refere ao item $b$ - apontado anteriormente, em termos da tendência do documento em visualizar a diversidade cultural como desvio, deficiência ou, simplesmente, como algo exótico - observa-se que, quando o mesmo aponta para o problema da formação docente, intitulado "Desconsideração das especificidades próprias dos níveis e/ou modalidades de ensino em que são atendidos os alunos da educação básica", o discurso que define tais "especificidades" é voltado predominantemente às "deficiências dos alunos", e não à pluralidade de saberes e universos culturais dos mesmos. Da mesma forma, ao falar de "princípios orientadores para uma reforma de formação de professores" - parte esta citada anteriormente, que vem logo após os problemas apontados e seguindo-se às definições de competências - observam-se alguns trechos em que se fala em "reconhecer e respeitar a diversidade cultural dos alunos"6, em "utilizar conhecimentos sobre a realidade econômica, cultural e político-social brasileira"7 e assim por diante. Entretanto, tal discurso permanece a nível de afirmações gerais, sem que as polêmicas esboçadas na primeira parte deste artigo, relativas a possibilidades de concretização do ideal multicultural, sejam levantadas. Da mesma forma, ao falar de identidade ${ }^{8}$, o discurso do documento trabalha com aspectos individuais, psicológicos envolvidos nessa categoria (fala-se, por exemplo, em "autonomia",

${ }^{6}$ BRASIL, 2000b, p. 49

${ }^{7}$ Id., Ibid., p. 50.

8 Id., Ibid., p. 69. 
"faixa etária" e assim por diante), sem que questões multiculturais relativas à construção identitária nas dimensões de gênero, raça e outras sejam mencionadas.

A visão da diversidade cultural como "deficiência" e, até mesmo, como um "problema", emerge com força no extrato a seguir, não deixando dúvidas quanto ao predomínio desta visão presente no discurso em pauta:

[A formação docente] deve desenvolver atitudes de acolhimento e respeito à diversidade, a partir da informação e conhecimento adquiridos pela familiaridade com a problemática de grupos diferenciados existentes na população brasileira: gêneros, etnias, culturas, portadores de necessidades especiais, religiões (BRASIL, 2000b, p. 70, grifo nosso).

As reflexões brevemente esboçadas acima suscitam, portanto, preocupações quanto ao papel da pesquisa e do multiculturalismo na formação docente, principalmente ao se traduzirem intenções - expressas no discurso da política curricular em pauta - em práticas de formação de professores, nos loci diferenciados agora destinados a essa função. Ao mesmo tempo em que registramos aspectos encorajadores, na medida em que pesquisa e diversidade cultural são temas apontados como relevantes na formação docente, podendo, portanto, representar pontos de partida para futuros desenvolvimentos curriculares na área, apontamos para a necessidade de discussões e trabalhos intensos na formação inicial e continuada de modo a evitar que binômios e contradições apontadas a nível discursivo possam se refletir em práticas de formação docente também elas ambíguas e pouco transformadoras.

\section{Conclusões}

A análise das diretrizes curriculares para a formação de professores da educação básica brevemente exposta no presente artigo evidenciou que, ainda que sensibilidades multiculturais e ênfases com relação ao papel da pesquisa possam emergir, esporadicamente, no discurso em pauta, os sentidos a elas atribuídos suscitam preocupações, na medida em que a diversidade cultural é percebida fundamentalmente em termos de deficiências e a pesquisa como uma dimensão prática, instrumental nesta formação. Tais ênfases diluem as possibilidades de se trabalhar uma formação docente multiculturalmente comprometida, tendo a pesquisa como eixo configurador de suas formulações.

Entretanto, a denúncia, por si só, não esgota os desafios de um modelo de professor pesquisador multiculturalmente comprometido, defendido por nós. Inicialmente, os desafios e a polissemia do multiculturalismo e da própria compreensão da articulação pesquisa-ensino remetem à necessidade de futuras pesquisas, que busquem aprofundar questões epistemológicas e metodológicas envolvidas nesse horizonte. Como exemplos de algumas dessas questões, citamos: $\bigcirc$ que, afinal, significa professor pesquisador multiculturalmente comprometido? Como se pensar em pesquisa, na formação docente, que não a "frature" em binômios (tais como pesquisa prática e pesquisa acadêmica), mas que a encare como um continuum? $\bigcirc$ que significa a pesquisa como fenômeno multicultural? Envolveria temas multiculturalmente orientados? Estratégias de pesquisa sobre formação identitária? Ou, além destas, também envolveria conteúdos específicos de formação, articulados a perspectivas de questionamento da sua constituição, enquanto seleção cultural? 
Se acreditarmos na pesquisa e no multiculturalismo como dimensões relevantes na formação docente em um mundo plural e desigual, temos que ir além das denúncias e buscar caminhos pelos quais a concretização desse ideal possa ser viabilizada. Esperamos que, em tempos de terrorismos e intolerâncias contra aqueles percebidos como "diferentes", a relevância da formação de professores como pesquisadores multiculturalmente comprometidos possa ser reconhecida nas novas agendas políticas brasileiras que se anunciam.

\section{Referências}

ANDRÉ, M. A. (Org.). O papel da pesquisa na formação e na prática dos professores. São Paulo: Ed. Papirus, 2001.

BRASIL. Ministério da Educação. Proposta de diretrizes para formação inicial de professores da educação básica, em cursos de nível superior. Brasília, DF, 2000b. Disponível em: <http://www.mec.gov.br/sesu/ftp/curdiretriz/ed_basica/ed_basdire.doc>. Acesso em: 2 ago. 2005.

CANEN, A. Avaliação da aprendizagem em sociedades multiculturais. Rio de Janeiro: Ed. Papel \& Virtual, 2001 a. Disponível em: < www.papelvirtual.com.br $>$. Acesso em: 2 ago. 2005.

Educação multicultural, identidade nacional e pluralidade cultural: tensões e implicações curriculares. Cadernos de Pesquisa: revista da Fundação Carlos Chagas, São Paulo, n. 111 , p. 12-23, 2000.

. Formação de professores: diálogo das diferenças. Ensaio: avaliação e políticas públicas em educação: revista da Fundação Cesgranrio, Rio de Janeiro, v. 5, n. 17 , p. 477 - 494, out./dez. 1997.

- Multiculturalismo e formação docente: experiências narradas. Educação e Realidade: revista da Faculdade de Educação da UFRGS, Porto Alegre, v. 24, n. 2, p. 89-102, 1999.

Sentidos e dilemas do multiculturalismo: desafios curriculares para o novo milênio. In: LOPES, A. R. C.; MACEDO, E. (Org.). Currículo: debates contemporâneos. São Paulo: Cortez, 2002. p. 174-195.

CANEN, A. Universos culturais e representações docentes: subsídios para a formação de professores para a diversidade cultural. Educação e Sociedade: revista quadrimestral de ciências da educação, Campinas, SP, n. 77, p. 207-227, 2001 b. 
CANEN, A.; ANDRADE, L. T. Construções discursivas sobre pesquisa em educação: o que falam professores formadores universitários. In: CONGRESSO DE LEITURA DO BRASIL, 13., 2001, Campinas; SEMINÁRIO SOBRE LEITURA E PRODUÇÃO NO ENSINO, 2., 2001, Campinas. Anais... Campinas, SP: Universidade Estadual de Campinas, 2001.

CANEN, A.; MOREIRA, A. F. (Org.). Enfases e omissões no currículo. São Paulo: Papirus, 2001.

CANEN, A.; OLIVEIRA, A. M. A. Multiculturalismo e currículo em ação: um estudo de caso. Revista Brasileira de Educação, Campinas, SP, n. 21 , p. 61-72, set./dez. 2002.

CONSElHO NACIONAL DE EDUCAÇÃO (Brasil). Conselho Pleno. Parecer n . 115, de 10 de gosto de 1999. Dispõe sobre os institutos superiores de educação. Atos

normativos, Brasília, DF, 1999. Disponível em: <http://portal.mec.gov.br/cne/index. $>$. Acesso em: 3 ago. 2005.

. Resolução $n^{\circ}$. 1, de 18 de fevereiro de 2002. Institui diretrizes curriculares

nacionais para a formação de professores da educação básica, em nível superior, curso de licenciatura, de graduação plena. Atos normativos, Brasília, DF, 2002. Disponível em:

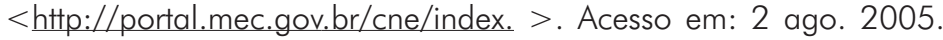

GILROY, P. O Atlântico negro. São Paulo: Editora 34, 2001.

GLAZER, N. We are all multiculturalists now. London: Harvard University Press, 1997.

GRANT, N., Multicultural education in Scotland. Edinburgh: Dunedin Academic Press, 2000.

HOOVER, L. Reflective writing as a window on preservice teacher's thought processes. Teaching and Teacher Education, Oxford, v. 10, n. 1, p. 83-94, 1994.

LÜDKE, M. (Coord.). O professor e a pesquisa. São Paulo: Papirus, 2001.

McLAREN, P. Multiculturalismo revolucionário. Porto Alegre: ArtMed, 2000.

PINTO, R. P. Diferenças étnico-raciais e formação do professor. Cadernos de Pesquisa, São Paulo, n. 108, p. 199-232, nov. 1999.

QUEIROZ, C. A ciência em debate. In: SIMPÓSIO INTERNACIONAL SOBRE ÉTICA E O FUTURO DA DEMOCRACIA, 1994, Lisboa. Actas... Lisboa: Edições Colibri, 1998. p. $451-458$.

WILSON, J. Preconditions for educational research. Educational Research, [London], v. 40, n. 2, p. $161-168,1998$.

Recebido em: 26/06/2004

Aceito para publicação em: 25/04/2005 